\title{
Aparecida y Evangelii Gaudium en esta hora de la Iglesia ${ }^{1}$.
}

\section{Cardenal Jaime Ortega y Alamino ${ }^{1}$}

${ }^{1}$ Arzobispo de La Habana

El alto honor que me confiere esta Universidad de Santa María La Antigua, su prestigio y su ubicación en el Istmo de Panamá, privilegiado cruce de caminos, donde la América luso-hispánica del Sur encuentra a la América hispanoparlante del Centro y del Norte del Subcontinente para abrirse ambas al amplio espectro cultural del Caribe, me lleva, al pronunciar mis agradecidas palabras de aceptación a este alto Centro de Estudios, a detenerme en dos realidades que subyacen y sustentan su quehacer académico, humanista y científico: La América Latina y la Iglesia Católica.

Contemplamos, aquí, con mirada propia, nuestra América, como tan acertadamente llamara José Martí a este conglomerado de pueblos y etnias que se extienden desde el Rio Grande hasta la Patagonia, y que parece colgar de ese arco de islas grandes o pequeñas de las Antillas que rematan por el norte, como el asa de un cesto, esa porción tan entrañable de humanidad.

Fue en esta América, donde los misioneros dominicos, franciscanos, jesuitas y otros, junto con la semilla evangélica, sembraron saber y generaron cultura.

Por todo esto, y para conocer el pensar y el sentir de la Iglesia en esta hora de América Latina considero, como premisa indispensable a este propósito, referirme en mis palabras, ante todo, a dos documentos eclesiales recientes. Uno, emanado de la V Conferencia General de los obispos Latinoamericanos en Aparecida, Brasil, el año 2007 y el otro la Exhortación Apostólica del Papa Francisco sobre la Evangelización de fecha 24 de noviembre de 2013.

Con ese fin les pido ante todo que fijen su atención en el pensar y el actuar del Papa Francisco, el Papa latinoamericano, debido a su influjo decisivo en la V Conferencia General del Episcopado de América Latina y el Caribe celebrada en Aparecida y en el documento conclusivo de esa Conferencia, así como por la impronta personal que nos deja en su Exhortación Apostólica Evangelii Gaudium (sobre la

\footnotetext{
${ }^{1}$ Conferencia pronunciada por S.E.R. Cardenal Jaime Ortega y Alamino, Arzobispo de La Habana, durante la entrega del Doctorado Honoris Causa en Humanidades y Ciencias Religiosas
} 
Invest. pens. crit.

Vol. 2, No. 5, septiembre-diciembre 2014.

pp. $99-108$

Evangelización). Su participación en aquel evento y en la generación de los dos documentos citados, lo convierten a un tiempo en puente entre ellos y plataforma de ambos.

Desde sus tiempos de joven sacerdote el padre Jorge Bergoglio asumió una actitud consecuente entre su fe, arraigada profundamente en el Dios del amor y la misericordia, y una visión del mundo llena de comprensión y aún de ternura. Sabía él que se trata de un mundo en el que no faltan los problemas, un mundo lleno de desafíos para la fe cristiana pero, al mismo tiempo, un mundo que, a menudo sin saberlo, tiene sed de Dios.

Esos rasgos del mundo actual se hacían muy evidentes en las circunstancias de tiempo y lugar en que se encontraron los obispos latinoamericanos al reunirse para la V Conferencia General del CELAM en Aparecida, Brasil.

Para esta gran asamblea nosotros nos reunimos muy cerca del Gran Santuario de la Virgen Aparecida, el más visitado de América Latina (más de 13 millones de peregrinos cada año). En repetidas ocasiones los obispos que intervenían en las diferentes sesiones de nuestra Asamblea hicieron notar el significado especial de la proximidad de nuestras reuniones a este Santuario y la gracia particular que nos aportaba esta cercanía, así como el eco que iba hallando progresivamente en los corazones de los participantes.

Entre aquellos que hicieron más de una vez referencia al ambiente creado por esta circunstancia estuvo precisamente el Cardenal Bergoglio. En este ambiente se gestó lo que pudiéramos llamar "el espíritu de Aparecida", que tuvo un extraordinario efecto bienhechor en los participantes, contribuyó al éxito de nuestro encuentro, y desempeñó un papel facilitador respecto al documento que emanó de aquella reunión.

Un observador de nuestra asamblea, perteneciente a otra confesión cristiana no católica, me decía la víspera de su partida algo anticipada: parto ahora para Ginebra para una reunión ecuménica que será muy diferente, y lo hago lleno de nostalgia; esa Eucaristía de cada mañana, la irradiación de la Virgen... y el pueblo... el pueblo, repitió admirado.

Definía así, sin proponérselo y de modo esquemático lo que fue "el espíritu de Aparecida":

- La Eucaristía (Dios con nosotros)

- La Virgen María (el acompañamiento de la Madre)

- El pueblo (el verdadero destinatario de aquel encuentro)

Para esta ocasión de la V Asamblea General del CELAM los obispos participantes no teníamos un documento preparatorio como lo hubo para las Asambleas precedentes, de Puebla y Santo Domingo.

En Aparecida los obispos nos reuníamos, una vez más, empleando el método ya tradicional del padre Pierre Cardijn: "Ver, juzgar, Actuar". Pero en el mismo comienzo de la Asamblea, aprobamos una proposición hecha, entre otros, por el Cardenal Bergoglio, de modificar el viejo método, a fin de 
introducir un matiz particular en el "Ver". Y así decidimos que nuestra mirada sobre la realidad tuviera en cuenta, ante todo, la mirada de Dios sobre el mundo.

De este modo, no se trataría simplemente de un análisis sociológico, económico o político del mundo latinoamericano, sino más bien de la valoración de un conjunto de consideraciones de todo tipo sobre la vida personal, familiar y social del latinoamericano, pero inspiradas y sostenidas en esta ocasión por la relación con Dios del hombre y la mujer de este continente.

\section{Ver}

Este primer paso nos imponía, pues, ante todo, una serie de preguntas respecto a la mirada de Dios a nuestro pueblo latinoamericano. Ese pueblo cuyos cantos a la Virgen Aparecida llegaban como un eco desde la Basílica que estaba a nuestro lado hasta nuestra sala de reuniones, acompañando en cierto modo nuestras reflexiones y decisiones.

No nos referíamos en ellas a una noción conceptual de pueblo, sin rostro ni figura, ni a un pueblo hipotético o idealizado, el pueblo estaba allí, junto a nosotros. La mirada de Dios sobre ese pueblo, que de cierta manera nosotros tomábamos prestada de Él, nos despojaba de criterios preconcebidos sobre su constitución y de prejuicios sobre la religiosidad simple y bella de esos hombres y mujeres. La mirada de Dios asumida por nosotros vivencialmente nos hacía comprender ante todo, la bienaventuranza de los pobres, viendo de cerca, tocando con nuestras manos la manera de enfrentar la vida del pueblo latinoamericano, en un clima de fe peregrinante, y aquella multitud fluyente no era homogénea en su composición social, sino una muestra variada de pueblo con predominio de los más pobres y sencillos.

La presencia de peregrinos a toda hora del día nos ponía de golpe ante hombres y mujeres innumerables y diversos que nos hacían compartir la compasión de Jesús sobre la multitud "que parece vagar como ovejas que no tienen pastor" (Mt 9, 36)

Aparecida se convirtió así para los obispos latinoamericanos y caribeños en algo más que en una reflexión teológica y sociológica sobre la Iglesia en América Latina, de la cual debía emanar un documento conclusivo para ser conocido y estudiado y que contendría en algunas páginas la estrategia pastoral para los años próximos.

Por lo que allí veíamos Aparecida debía constituir una respuesta de fe humilde y comprometida de la Iglesia latinoamericana y caribeña a los reclamos de espiritualidad del hombre y la mujer de hoy en nuestro continente, un esfuerzo serio por saciar la sed de Dios que hay en nuestros pueblos. Una respuesta formulada en espíritu evangélico, con palabras que expresan la misericordia de Dios y la comprensión de una Iglesia que invita a todos a una conversión sincera a Cristo para tener en El vida abundante, para hallar en El inspiración, fortaleza y sentido para la vida. 
Invest. pens. crit.

Vol. 2, No. 5, septiembre-diciembre 2014.

pp. $99-108$

Allí, en Aparecida, comprendimos también, existencialmente, el papel maternal de María en el plan de la Salvación. Ella nos lleva a Jesús. Nos reúne alrededor de su Hijo.

\section{Juzgar}

En Aparecida tratamos de ver la realidad desde lo alto, con la mirada de Dios. Esto nos llevó a hacer un juicio de orden más bien trascendente, no simplemente antropológico, inmanente, que puede hacernos deslizar fácilmente hacia lo social o lo político como factores principales en el desarrollo y la marcha de los conglomerados humanos. Las condiciones de nuestra reflexión nos hicieron evitar ese riesgo.

Es evidente que debemos tener en cuenta necesariamente esas realidades pero, ante los reclamos de nuestro pueblo, sus carencias personales y sociales y su búsqueda de espiritualidad, el anuncio del Reino de Dios ocupaba para nosotros, pastores de la Iglesia, el centro de la escena.

Por esto teníamos que detenernos, como lo hacía Jesús mismo, en los males que anidan en el corazón del hombre, como son la falta de amor y de sentido para la vida, el vacío espiritual, la ausencia de Dios.

Ver al hombre con la mirada de Dios significa pues emitir un juicio sobre el hombre teniendo en cuenta su relación con Dios, su apertura a la trascendencia, todo esto tan olvidado por analistas de otras disciplinas. Ahora bien, ese juicio estaría además impregnado de misericordia y comprensión, al modo en que Dios mismo nos juzga a nosotros. "Yo no he venido para condenar, sino para salvar al mundo" (Jn 12, 47).

\section{Actuar}

Nuestra acción como Iglesia en ese mundo será, consecuentemente, dejarnos llevar por el Espíritu Santo que nos conduzca hacia una búsqueda creativa de caminos a seguir. En este quehacer deben comprometerse obispos, sacerdotes, laicos y personas consagradas para tratar de colmar el vacío de los corazones, para combatir la ausencia de Dios de las estructuras familiares, sociales y políticas, no sólo por medio de la presentación de proyectos moralizantes o por la exaltación de los valores personales, familiares y sociales según la tradición cristiana, sino mediante el anuncio claro y valiente de Cristo a los hombres y mujeres de hoy (parresia).

Este anuncio del Reino de Dios debe constituir siempre una noticia agradable, pero inquietante.

Nuestra modernidad, nuestra actualización misionera no pueden consistir tampoco en la aprobación y difusión de sucedáneos del Evangelio, que parezcan interesar a las nuevas generaciones, con el fin de atraer su atención hacia la religión como elemento todavía válido para el hombre actual. Debemos encontrar, más bien, con celo creativo, los medios de hacer descubrir a ese hombre la sed de Dios que 
él lleva en sí mismo, y anunciarle a Jesucristo, fuente de agua viva, con palabras convincentes y testimonios conmovedores, capaces de llegar al hombre y la mujer de hoy. Santa Teresa de Jesús lo dirá con una simple sentencia: "En las cosas de Dios no se trata tanto de pensar como de amar".

La Conferencia de Aparecida tuvo lugar en el año 2007 con la presencia del Papa Benedicto XVI. Cinco años más tarde, tuvo lugar la renuncia a la Sede de Pedro del Papa Benedicto.

La decisión del Papa Ratzinger de dejar su carga de pastor universal y sucesor de Pedro al frente de la Iglesia Católica, después de su primer efecto sorprendente y aún doloroso para muchos cristianos, lanzó al mundo de hoy un llamado estremecedor al realismo, a la humildad, a la transparencia, actitudes todas deficitarias en el momento actual de la historia. Por este mismo hecho comenzaba un nuevo período en la vida de la Iglesia. El gesto que culminaba su pontificado iniciaba al mismo tiempo la renovación de la Iglesia.

Los cardenales fueron convocados al cónclave. No había precedente para una reunión de este género. Los papas habían fallecido siempre cuando los cardenales se reunían para elegir un nuevo pontífice. Pero ahora el Papa vivía aún y nosotros no sabíamos ni siquiera cuál sería el tratamiento correcto para el antiguo pontífice, ni el nombre que se le daría a su nueva situación. Era un contexto inédito para un cónclave que resultaría diferente.

Los nueve días reglamentarios después de la muerte de un Papa para comenzar el cónclave fueron aceptados analógicamente como período mínimo para comenzar nuestro cónclave. Estábamos procediendo en todo momento por analogía, según la Constitución Apostólica "Universae dominici gregis" del Papa Juan Pablo II que no hacía ninguna alusión al caso de la renuncia de un Papa, sino que suponía siempre la muerte del Sumo Pontífice para convocar un cónclave, así como los nueve días de luto, durante los cuales los cardenales llegarían a Roma para participar en las misas rituales por el Pontífice fallecido y para sostener al mismo tiempo los encuentros preparatorios para el cónclave.

En esta ocasión teníamos los cardenales todo el tiempo necesario para intercambiar opiniones sobre la Iglesia en el mundo actual y para trazar todos juntos el perfil del Pontífice que necesitaba la Iglesia para este momento de la historia.

Fueron reuniones de gran fraternidad en un clima de total libertad. Las palabras mismas de Benedicto XVI en su carta de renuncia, haciendo notar que la Iglesia necesitaba "un hombre fuerte de cuerpo y de espíritu, capaz de conducir la barca de Pedro y de anunciar el Evangelio al mundo de hoy, sometido a rápidas transformaciones y sacudido por cuestiones de gran relevancia para la vivencia de la fe", contribuían también a dibujar el perfil esencial de su sucesor.

En ese clima de búsqueda, y sabiendo que el Espíritu Santo nos llevaría a elegir el Papa que la Iglesia necesitaba, escuchamos la voz de numerosos cardenales. Todos describían las tareas del nuevo pontífice y proponían los mejores modos de cumplirlas. En general todos deseaban una Iglesia renovada, 
Invest. pens. crit.

Vol. 2, No. 5, septiembre-diciembre 2014.

pp. $99-108$

centrada en su misión evangelizadora, capaz de ser comprendida, escuchada, tenida en cuenta por el mundo de hoy.

Entre las voces que escuchamos hubo una, breve y precisa. Fue la intervención del Cardenal Bergoglio.

Para un cardenal latinoamericano, como yo, las palabras del Cardenal Bergoglio eran un eco de la V Conferencia del CELAM tenida en Aparecida, Brasil, en mayo del año 2007. El Cardenal, que había tenido una participación decisiva en esa Asamblea y en la redacción del importante documento conclusivo de este encuentro eclesial, el mejor texto de todos los emanados de las anteriores conferencias generales del Episcopado Latinoamericano, en el cual dejó su impronta personal, estaba diciendo a los electores del nuevo pontífice que el programa diseñado por la Iglesia Latinoamericana en Aparecida era el mismo que él consideraba válido para la Iglesia Universal en el futuro.

Inspirado en la Exhortación Apostólica "Evangelii Nuntiandi” del Papa Pablo VI, el Cardenal Bergoglio dijo que "la evangelización es la razón de ser de la Iglesia" y mencionó "la dulce y reconfortante alegría de evangelizar, insistiendo en la acción del mismo Cristo, que desde dentro nos empuja a hacerlo".

Voy a citar las palabras pronunciadas en esa ocasión por el Cardenal Bergoglio, porque transcurrido ya un tiempo del inicio de su Pontificado estamos preparados para constatar que esas palabras pronunciadas por el Cardenal, no constituían solamente un resumen de las conclusiones de Aparecida, sino también las ideas-fuerza de lo que sería su pontificado y del contenido de la exhortación apostólica Evangelii Gaudium del Papa Francisco.

He aquí sus palabras:

- Se hizo referencia a la evangelización. Es la razón de ser de la Iglesia.

- "La dulce y confortadora alegría de evangelizar" (Pablo VI).

- Es el mismo Jesucristo quien, desde dentro, nos impulsa.

1.- Evangelizar supone celo apostólico. Evangelizar supone en la Iglesia la parresía de salir de sí misma. La Iglesia está llamada a salir de sí misma e ir hacia las periferias, no solo las geográficas, sino también las periferias existenciales: las del misterio del pecado, las del dolor, las de la injusticia, las de la ignorancia y prescindencia religiosa, las del pensamiento, las de toda miseria.

2.- Cuando la Iglesia no sale de sí misma para evangelizar deviene autorreferencial y entonces se enferma (cfr. La mujer encorvada sobre sí misma del Evangelio). Los males que, a lo largo del tiempo se dan en las instituciones eclesiales tienen raíz de autorreferencialidad, una suerte de narcisismo teológico.

En el Apocalipsis Jesús dice que está a la puerta y llama. Evidentemente el texto se refiere a que golpea desde fuera la puerta para entrar... Pero pienso en las veces en que Jesús golpea la puerta desde dentro 
para que le dejemos salir. La Iglesia autorreferencial pretende a Jesucristo dentro de sí y no lo deja salir.

3.- La Iglesia, cuando es autorreferencial, sin darse cuenta, cree que tiene luz propia; deja de ser el "mysterium lunae" y da lugar a ese mal tan grave que es la mundanidad espiritual (Según De Lubac el peor mal que puede sobrevenir a la Iglesia). Ese vivir para darse gloria unos a otros.

Simplificando; hay dos imágenes de Iglesia: la Iglesia evangelizadora que sale de sí; la Dei Verbum religiose audiens et fidenter proclamans, o la Iglesia mundana que vive en sí, de sí, para sí.

Esto debe dar luz a los posibles cambios y reformas que haya que hacer para la salvación de las almas.

4.- Pensando en el próximo Papa: un hombre que, desde la contemplación de Jesucristo y desde la adoración a Jesucristo ayude a la Iglesia a salir de sí hacia las periferias existenciales, que la ayude a ser la madre fecunda que vive de "la dulce y confortadora alegría de evangelizar".

(Hasta aquí las palabras del cardenal Bergoglio antes del Cónclave).

Los primeros pasos del Papa Francisco, que incluyen evidentemente la elección de su nombre, nos indican que el soplo renovador de la Iglesia que se traslucía en las intervenciones de la mayoría de los cardenales en las sesiones previas al cónclave había comenzado ya a hacer sentir sus efectos.

El estilo del nuevo pontífice conquistaba el mundo por la proximidad del Papa Francisco al pueblo, así como por su lenguaje directo y sus gestos y referencias hacia los “descartados" de la sociedad.

El mismo Papa mostró muy pronto el tipo de Iglesia que él quería presentar al mundo: una Iglesia pobre, abierta a todos, que sale de sí misma para alcanzar a todos, especialmente a los pobres, los enfermos, los débiles, los más desfavorecidos de la sociedad.

Una Iglesia consciente de su misión evangelizadora, en la cual deben comprometerse obispos, sacerdotes, religiosos, religiosas y laicos. Esta es la Iglesia presentada de manera precisa en el documento conclusivo de Aparecida, la que él mismo, como cardenal que vino a participar del cónclave, había propuesto a sus hermanos cardenales como ideal al cual debía tender la Iglesia en un futuro inmediato.

\section{La Exhortación Apostólica "Evangelii Gaudium”}

Es suficiente una rápida ojeada a la tabla de materias de la exhortación apostólica Evangelii Gaudium para darse cuenta que, desde el título sugerente de la exhortación que presenta la evangelización como una fuente de alegría para proclamar la buena noticia, hasta el último número del texto en el que presenta a María como Madre de la Evangelización, el Papa Francisco habla del anuncio del Evangelio y destaca en los primeros números las características de esa alegría que renueva al mismo evangelizador, con su efecto dulce y reconfortante para quienes emprenden esta tarea. 
Invest. pens. crit.

Vol. 2, No. 5, septiembre-diciembre 2014.

pp. $99-108$

Ese llamado a la alegría de evangelizar introduce un texto que describe una Iglesia evangelizadora, misionera que el Santo Padre gusta llamar "una Iglesia en salida", en la cual todos los que la integran, obispos, sacerdotes y laicos deben participar para que la misión sea una acción verdaderamente comunitaria, sin esperar que los hombres y mujeres del medio donde la Iglesia se halla vengan a la comunidad eclesial, sino yendo hasta donde ellos están, incluso y sobre todo a las periferias de la sociedad.

Aquí se descubre fácilmente el pensamiento del Papa Bergoglio y las huellas dejadas por él en Aparecida: Y el Santo Padre combate seguidamente las tentaciones del misionero, que están presentes en muchos cristianos de hoy: el pesimismo, la acidia egoísta, que es la aridez y el cansancio espiritual, la mundanidad espiritual, que consiste en tomar del mundo que nos rodea modos de pensar y de sentir ajenos a nuestra fe.

Inmediatamente el Papa pasa a exponer las condiciones y las modalidades del anuncio evangélico y habla de una evangelización que debe tener siempre en cuenta el kerigma, principalmente por medio de homilías bien preparadas. En esta parte el Santo Padre se extiende en explicar el modo de ejercer el ministerio de la predicación por parte de sacerdotes, diáconos, catequistas u otros ministros, de modo que el anuncio de Jesucristo se haga con claridad, pero al mismo tiempo con profundidad.

Al hablar de la integración social de la evangelización la exhortación apostólica lo hace también en clave misionera, de tal modo que el evangelizador busque en el anuncio de Cristo al mundo, sus repercusiones sociales, por ejemplo, haciendo notar en el anuncio de Jesús la preocupación del Señor por los pobres.

La exhortación proclama además que la confesión de fe no es verdaderamente auténtica ni no existe ningún compromiso social del evangelizador, pues la Iglesia necesita ese compromiso para que el anuncio sea creíble.

Una preocupación siempre presente en las palabras y en la acción pastoral del Papa Francisco como sacerdote y como obispo es reclamada como condición necesaria para la evangelización en la exhortación apostólica: es la integración social de los pobres, cuyo grito debemos escuchar en toda fidelidad al Evangelio, si nos mantenemos unidos a Dios.

El diálogo de los cristianos con el mundo de la ciencia, el diálogo ecuménico, con el judaísmo y con otras religiones debe ser parte del diálogo social del creyente en Jesucristo como una contribución a la fraternidad y a la paz constituyen un medio importante de evangelización.

El Papa Francisco invita fraternalmente a todos los católicos del mundo a hacerse evangelizadores llenos del Espíritu Santo, apegados a Cristo y plenamente conscientes de formar parte de un pueblo, el pueblo de Dios que se pone en marcha para anunciar con gozo el Evangelio al mundo, acompañado por María, Madre de la evangelización y don precioso que Jesús ha hecho a su pueblo. 
Leyendo con atención la exportación apostólica Evangelii Gaudium también encontramos, en su conjunto, los temas tradicionales que la Iglesia propone a través del magisterio de los Papas y obispos del pasado siglo, y sin embargo hay un soplo interior que anima sus consideraciones y propuestas y esto es fruto de lo que hemos dado en llamar el "espíritu de Aparecida", pero también del pensamiento luminoso del Papa Francisco con relación al mundo de hoy y a la presencia de la Iglesia en este mundo: Eso lo había mostrado ya en vísperas del cónclave en el cual fue electo para la Sede de Pedro.

Otros factores de orden espiritual y pastoral como el amor del Papa Bergoglio a los pobres, injertado en su pobreza personal, su experiencia como sacerdote y obispo en Argentina y su devoción a la Santísima Virgen María dejan también sus huellas en la última Exhortación Apostólica.

Una mención especial merece la profunda devoción del Santo Padre a la Virgen María en el contexto de su Exhortación Apostólica y ésta debe ser destacada aquí en esta Universidad puesta bajo la mirada de Santa María. En la espiritualidad del Santo Padre María ocupa un lugar relevante, sobre todo con relación a la experiencia inolvidable de Aparecida, en la cual la Virgen desempeñó un papel similar a su acompañamiento a los apóstoles en la espera de Pentecostés. En este sentido él ha dicho que María fue protagonista en Aparecida.

En efecto, las manifestaciones innumerables de religiosidad popular que la Virgen es capaz de suscitar de modo asiduo, teniendo en cuenta las potencialidades que esta religiosidad contiene en medio de nuestro mundo post-moderno, nos descubren un papel renovado de María en este mundo nuestro, cargado de desarrollos científicos y técnicos deslumbrantes, pero débil y desorientado, donde el hombre actual está en búsqueda de paz, de felicidad y de sentido para la vida. El amor convocante de la Virgen María conduce hasta su Hijo a aquellos que están, sin saberlo, sedientos de Dios.

En Aparecida descubrimos en el rol maternal de María, su diligencia amorosa para detectar, como en las bodas de Caná, dónde se encuentra realmente "el vino que falta" al hombre de hoy, como son sus necesidades más profundas, sus expectativas fallidas, su falta de esperanza, su incansable búsqueda de felicidad y la ausencia de Dios en el horizonte de su vida.

Al concluir, podemos considerar legítimamente que el programa trazado por Aparecida a la Iglesia latinoamericana y caribeña, donde el Cardenal Bergoglio ha dejado su huella y del cual quiso hacer un precioso resumen a los electores del nuevo pontífice, se desarrolló después en la primera Exhortación Apostólica del Papa Francisco como programa válido que él propone para una Iglesia renovada en el mundo futuro. La Evangelización es la oferta obligada de la Iglesia al mundo y nadie más puede brindarla, para que el hombre halle la verdad sobre sí mismo, para que llegue a existir la justicia, y la Paz sea una realidad en la convivencia humana.

El primer papa latinoamericano, cargado de experiencia pastoral en su país de origen, la Argentina, propone a la Iglesia Universal el programa evangelizador para el futuro de la humanidad, cuyo contenido es esencialmente el que la Iglesia de Latinoamérica y el Caribe se propuso para la evangelización de esta parte del mundo en Aparecida y en el cual él mismo, como participante principal, había dejado 
Invest. pens. crit.

Vol. 2, No. 5, septiembre-diciembre 2014.

pp. 99-108

su impronta personal, tanto en sus intervenciones, como en la redacción final del documento. Esta realidad novedosa ha dado a Nuestra América un papel de primer plano en el anuncio de Jesucristo al hombre y a la mujer de cualquier latitud de nuestro mundo.

Es esto lo que he querido resaltar como cardenal cubano, oriundo de estas tierras nuestras, al recibir este alto honor que la Universidad de Santa María La Antigua, ubicada en el corazón de Nuestra América, me confiere.

Muchas gracias. 